Int. J. Dev. Biol. 52: 383-388 (2008)

doi: $10.1387 / \mathrm{ijdb} .072448 \mathrm{fr}$

\title{
Calpain 2 expression pattern and sub-cellular localization during mouse embryogenesis
}

\author{
FABRICE RAYNAUD ${ }^{1}$, ANNE MARCILHAC ${ }^{1}$, KARIM CHEBLI $^{2}$, YVES BENYAMIN ${ }^{1}$ and MIREILLE ROSSEL ${ }^{3, *}$ \\ ${ }^{1}$ Laboratory Cellular Motility EPHE CNRS UMR 5539, University Montpellier, ${ }^{2}$ IGMM, UMR 5535, IFR122 and ${ }^{3}$ Laboratory Quantitative \\ Cellular Biology EPHE, Montpellier 34095 INSERM U881 cc103, Montpellier 34095, University Montpellier, France
}

\begin{abstract}
Regulation of migration and proliferation by calpain has been shown in various cell types; however, no data are available concerning calpain 2 (CAPN2) localization in embryonic tissues. Here, we report the expression pattern of CAPN2 during mouse embryonic development. Expression of the capn2 gene is observed throughout embryonic development. From ES cells and the 8-cell stage to late neurulation stages, CAPN2 is expressed in the cytoplasm and nuclear compartments, with a clear co-localisation with chromatin. Whole-mount in situ hybridization analysis from E8.5 to $\mathbf{1 4 . 5}$ stages indicates high levels of capn2 expression in the nervous system, heart and mesodermal tissues. Up-regulation is maintained during later developmental stages in proliferating cells and in precursor cells involved in muscle (myoblasts) or bone formation (chondrocytes). At later developmental stages, elevated mRNA levels coincided with CAPN2 nuclear localization in these cell types, while differentiated cells maintained cytoplasmic expression. This detailed analysis reveals dynamic expression: nuclear localization was associated either with active cell mitosis in embryonic stem cells and early developmental stages or with precursor cells later during organogenesis. Thus, these data indicate that CAPN2 may represent a key factor in development from the first cell division.
\end{abstract}

KEY WORDS: calpain2, mouse embryogenesis, subcellular localisation

\section{Introduction}

The calpain family of proteases has been associated with multiple functions such as migration, adhesion, and apoptosis. The key function of calpain 2 (CAPN2) in cell motility was demonstrated by the potential of talin proteolysis and consequently the regulation of dynamic adhesion (Franco et al., 2004). However, recent data suggest a role in cell cycle regulation, specifically during mitosis (Honda et al., 2004). Several studies have shown that calpains play a role in the proteolysis of nuclear transcription factors associated with proliferation and progression through the cell cycle such as c-Myc, p53, Jun and Fos (Carillo et al., 1996, Huttenlocher et al., 1997, Watt and Molloy, 1993, Welm et al., 2002). Moreover calpains are involved in proteolysis of cyclin proteins such as cyclin D1 (Qin et al., 2003).

Targeted inactivation of capn2 leads to the death of homozygous mutants after the first zygote divisions (Dutt et al., 2006). These recent data indicate an essential role of capn2concerning cell survival during development. We have shown previously that
CAPN2 is localized in the nucleus of proliferating myoblasts (Raynaud et al., 2004) and proliferating cells in the adult brain (Konig et al., 2003). In quiescent myoblasts (G0 phase), cytoplasmic, but no nuclear localization was detected. The close association between CAPN2 and chromosomes suggests a possible role in the regulation of mitosis (Raynaud et al., 2004).

In order to assess the presence of CAPN2 during development, for which no data were available yet, we analyzed the expression pattern and the sub-cellular localization in mouse embryos.

\section{Results and Discussion}

We examine the localization of calpain 2 at the protein and mRNA levels between the first cell divisions and E14.5 days of mouse development. In situ hybridizations with murine and hu-

Abbreviations used in this paper: CAPN, calpain; ES, embryonic stem; ISH, in situ hybridization.

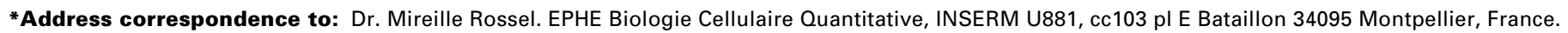
Fax: +33-4-6714-3928. e-mail: mrossel@univ-montp2.fr
} 
man probes were performed in parallel and gave identical results.

\section{Cytoplasmic and nuclear localisation of CAPN2 at early developmental stages}

As no data concerning protein distribution during embryonic development were available, our study relies on a report showing that capn2is necessary for the survival of the 8-cell stage embryo (Dutt et al., 2006). As the question of the presence and localiza-
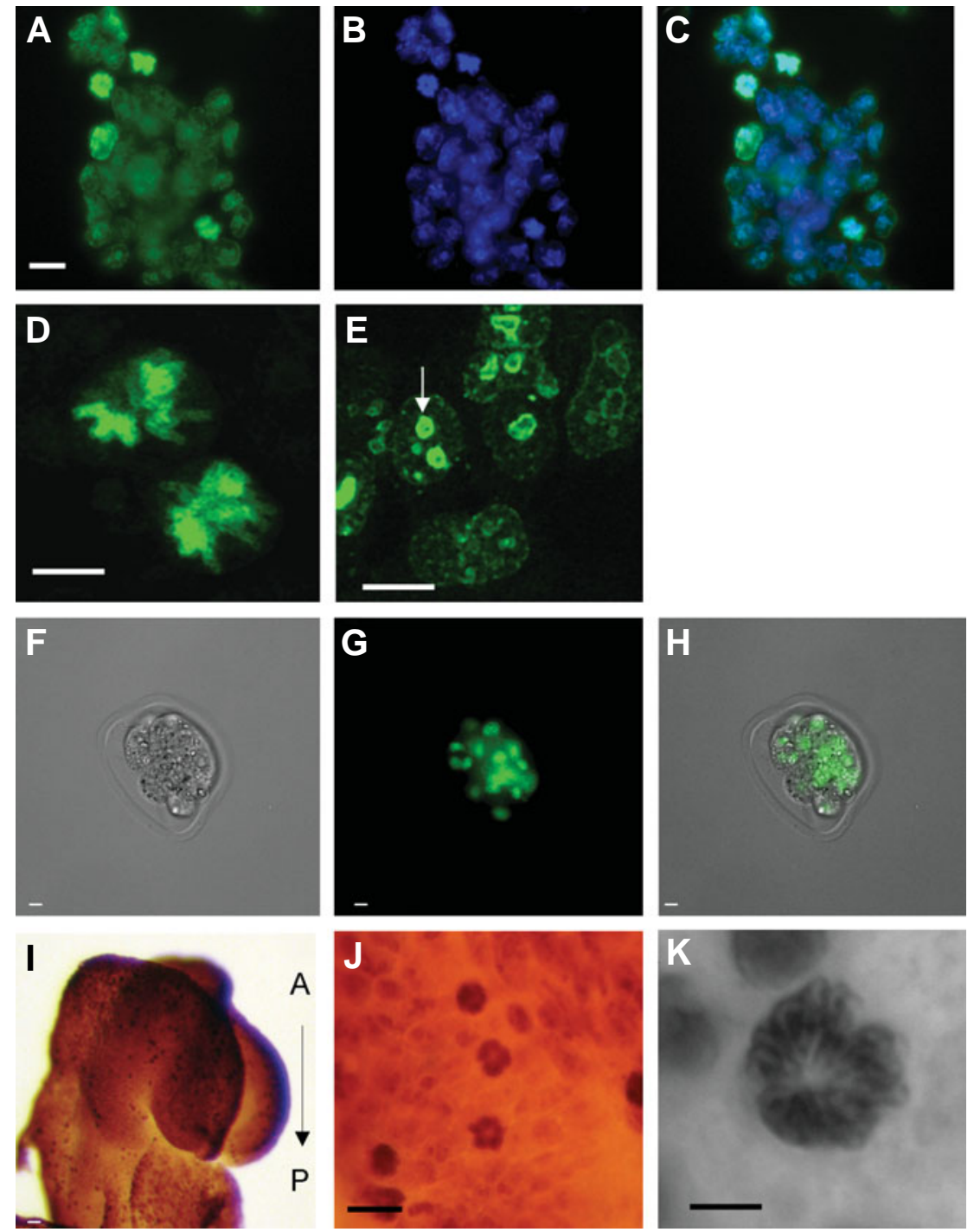

Fig. 1. Nuclear localization of CAPN2 during early developmental stages: from ES cells to E 8.5 embryo. CAPN2 expression was observed in all ES cells (A-E) in the cytoplasm as well as in the nucleus; green in (B,C). Nuclei position was assessed with DAPI nuclear staining (B). The close association of CAPN2 with DNA and in particular with chromosomes during metaphasis highlights the nuclear localization (D). These high magnification images were taken at low gain to avoid saturation of the detector by the intense chromosomal signal; as a consequence, the weaker cytoplasmic signal is not visible here (D-E). (E) Nucleolus labelling (arrow). CAPN2 expression was observed in all cells of 8-cell stage embryo with a strong nuclear signal (F-H). (F) Image with transmission light; (G) same embryo with fluorescent staining; (H) merged image. Whole-mount immunohistochemistry at E 8.5 (I-K). CAPN2 labelling was observed within the whole embryo (I) with very dark spots corresponding to mitotic figures (metaphases plate) with condensed chromosomes [antero -posterior $(A-P)$ orientation is indicated]; higher magnifications of chromosome labelling (J,K). Scale bars, $10 \mu \mathrm{m}$. tion of the protein was essential to analyze at very early stages, CAPN2 expression was explored in ES cells. The 8-cell stage esponds to the beginning of compaction process that will lead to fully compact morula embryo. This stage was important to embryo.

In mouse ES cells (Fig. 1A-E) as well as 8-cell embryos (Fig. $1 \mathrm{~F}-\mathrm{H}), \mathrm{CAPN} 2$ (green) is localized in the cytoplasm and in the nucleus. Close association with chromosome DNA (DAPI staining) was particularly prominent in mitotic figures and in particular when metaphase plate was observed (Fig. 1 A,C,D). We also performed immunohistochemistry on whole embryo at E8.5: CAPN2 was expressed ubiquitously with intense labelling in mitotic cells (Fig. 1I-K) throughout the embryo.

\section{Expression of the capn2 gene between E8.5 and E11.5}

Expression pattern of capn2was studied from embryonic day 8.5 to 11.5 (E8.5-E11.5) by In situ hybridization (ISH) in whole-mount embryos.

At E8.5 and E9.5, capn2 expression is observed in most tissues with high mRNA levels in the nervous system, heart and somites (Fig. $2 A, B)$. In order to obtain a more detailed view of the somite expression at E9.5, vibratome sections were performed and counterstained with DAPI nuclear marker to outline the tissue after the ISH processing (Fig. 3A-E). Sagittal sections through the whole-mount preparation of E9.5 embryos indicated restricted expression in the ventral half of the somites, while in the dorsal part of the somites no signal could be detected (Fig. $3 C-E)$. The ventral region will give rise to the sclerotome progenitors and is specified as early as E9.5 by transcription factor expression (Goldman etal., 2000; Tam etal., 2000). At E10.5 (Fig. 2 C,D) and E11.5 (Fig. 2E), capn2 mRNA labelling was also found at high levels within the whole embryo with particularly strong labelling of the limb buds, the branchial arches and somites (Fig. 2 C,D) and in the telencephalic ventricular zone (Fig. 2 D). At these early developmental stages, capn2 expression was relatively broad and present in cells with elevated proliferation, most tissues, or intense cell migration or organogenesis (limb buds, heart, somites).

\section{Restricted intense expression at later devel- opmental stages}

At later developmental stages (E14.5), frozen sections were performed. Elevated capn2mRNA signal was detected in restricted cell types (Fig. $4 A-I)$. We observed strong expression in myoblasts engaged in muscle fiber formation. Cell identity was assessed using a myoD probe on serial sections of the same embryos (Fig. 4B). Myoblasts expressing myoD were also positive 

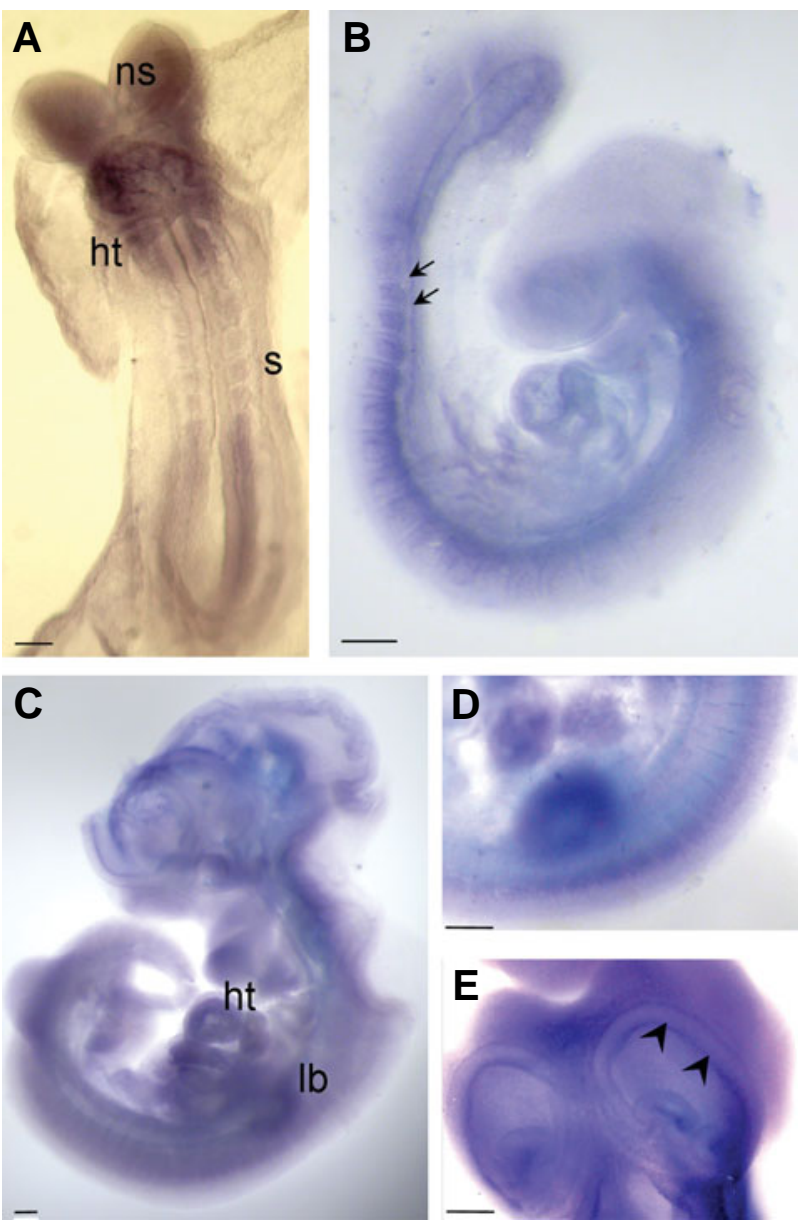
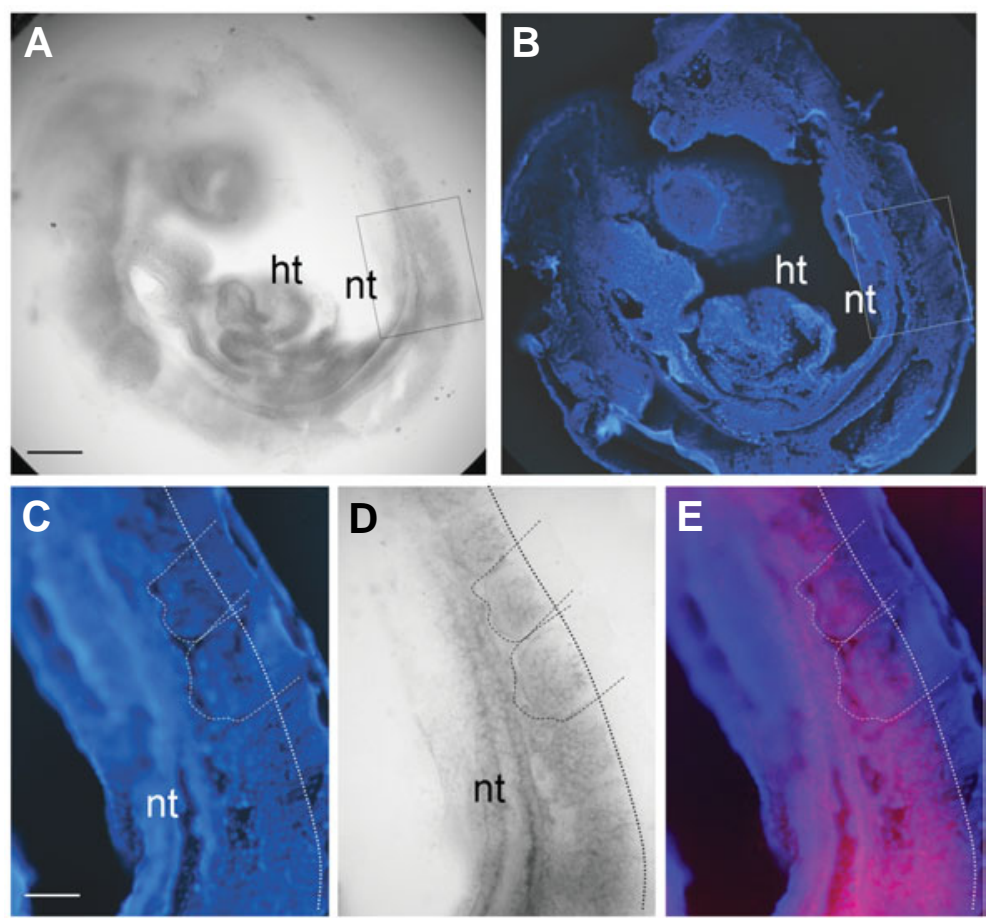

Fig. 3. Expression of calpain2 in the somites of an E9.5 embryo. Sagittal vibratome sections $(30 \mu \mathrm{m})$ through a hybridized $E 9.5$ embryo (A,D) counterstained with DAPI $(\mathbf{B}, \mathbf{C})$. Expression was confined to the ventral part of the somites and the adjacent neural tube (A-B). Higher magnification of the somites (C-D) and a combined image (E). The dotted line indicates the capn2 expression limit. Expression is mostly detected in ventral mesodermal cells. Columnar epithelial cells of the dorsal half are devoid of signal (C-E). $n t$, neural tube; $h t$, heart. Scale bars, $70 \mu \mathrm{m}(A, B), 12 \mu \mathrm{m}(C-E)$.

Fig. 2. Expression of calpain2 in whole-mount E8.5-11.5 embryos. Whole-mount in situ hybridization at E8.5 (A), E9.5 (B), E10.5 (C,D) and E11.5 (E). (A) mRNA is detected within the nervous system (ns), heart (ht) and somites (s). At E9.5 capn2 expression is observed within the whole embryo and at a higher level in the mesoderm: the somite boundaries are highlighted; see arrows in (B). At E10.5, capn2 mRNA was maintained at high levels in the heart (ht) and the limb buds (Ib) (C). Higher magnification of the somites (D). At E11.5 (E), capn2 expression underlined the ventricular surface within the forebrain (arrowheads). Scale bars, $70 \mu \mathrm{m}(A-D), 140 \mu \mathrm{m}(E)$.

for the capn2 probe (Fig. 4A-B, arrowheads). The expression of both genes, myoD and capn2, is coherent with previous studies on the regulation of human capn2transcription by myoD/myogenin (Dedieu et al., 2003). This regulation is probably conserved during mouse development. Identical patterns were found for the thoracic muscle cell precursors, the shoulder muscles ( $D$, arrow), the tongue and limb muscles (data not shown).

Capn2was also expressed in a specific cell type, the chondrocytes within the cartilage primordia of the ribs (Fig. 4A-C arrows). On longitudinal sections of the developing forelimb, strong expression was noticed at the chondrocyte level. (Fig. 4E-F). Within the growing bone, a specific proliferative area, the growing plate of the epiphysis, is characterized by proliferation of chondrocytes and their hypertrophy. This typical feature was clearly recognizable and capn2expression was maintained in hypertrophic chondrocytes (Fig. 4F). Nuclear localisation of CAPN2 in chondrocytes was also clearly observed on bone sections. It has been shown that calpains are necessary for the cartilage mineralization mediated by chondrocytes. This mineralization process occurs through proteoglycan proteolysis achieved by calpain activity (Yasuda et al., 1995). Capn2 is involved in the major remodelling occurring during cartilage growth. In vitro studies using mouse pre-osteoblasts indicated that CAPN2 activity increases during differentiation of osteoblastic cells and is regulated by Bone Morphogenic Proteins, which are well-known regulatory factors throughout embryogenesis (Murray et al., 1997).

Restricted capn2 expression was observed in the nervous system. At this stage, the brain has undergone extensive morphogenic changes generating complex neural structures where cellular differentiation is progressing. The proliferation at the hindbrain-spinal cord level has decreased by E13.5- E14.5 (Haubensak et al., 2004) and is limited to small regions. Capn2 positive cells were then confined to few positive cells in the ventricular zone of the neural tube (Fig. 4G,H). Moreover sub-cellular localisation indicates that cytoplasmic CAPN2 was observed in post-mitotic neurons in the mantle region, while nuclear staining was observed in ventricular precursors (Fig. 5A, arrows). Neither dorsal root ganglia nor cranial ganglia were labelled except the trigeminal ganglion, where all cells showed capn2mRNA (Fig. 4I).

Taken together, our results suggest that capn2 is highly expressed both in proliferating precursor cells and in differentiating cells in a transition process (chondrocytes, migrating myoblasts). 
We have previously demonstrated that the sub-cellular localization of CAPN2 in the myoblast cell line C2.7 is correlated with the quiescent versus proliferating status of the cells: nuclear localization was associated with proliferation while cytoplasmic localization was linked to quiescent and differentiating conditions (Raynaud et al., 2004).

In order to further assess the physiological meaning of these previous results, we analyzed the sub-cellular localization of CAPN2 in primary embryonic explants.

\section{Sub-cellular localisation and differentiation status}

To further analyze the relationship between proliferation and nuclear localization, we used primary culture of embryonic cells from various tissues of E10.5 embryo.

Neural tube explants from the head region generated neurosphere-like structures. After one day in culture, cells started to differentiate into neurons extending neuritic processes and expressing beta3tubulin (Fig. 5D-F). We performed double labeling with CAPN2 and anti-beta3tubulin antibodies. Nuclear CAPN2 (red, arrowheads) was never observed in post-mitotic beta3tubulin (green, arrows) positive neurons (Fig. 5D-F). In a previous study, we reported nuclear CAPN2 expression in adult nervous tissue. Interestingly, expression was mainly observed in areas where adult neurogenesis is happening, namely the rostral migratory stream toward the olfactory bulb and the subventricular zone of the striatum (König et al., 2003). Nuclear localization of CAPN2 may therefore be considered as a marker of neural proliferating cells in embryonic as well as adult tissues. CAPN2 nuclear localization and activity have been demonstrated in cerebellar granule cells in culture. In granule cells, nuclear activity is associated with selective CaMKIV proteolysis (Tremper-Wells and
Vallano, 2005).

Explants from the trunk and caudal region were used to generate primary myoblast cultures. Myoblast labelling was comparable to that of neuronal cells: undifferentiated cells showed nuclear CAPN2 expression (Fig. 5G-I, green). Co-labelling with myoD transcription factor assessed myoblast identity (red). The merge figure shows that both markers co-localized (Fig. 5I, arrow), whereas some fibroblasts were labelled by CAPN2 only (Fig. 5I, arrowhead). Our results are in agreement with the previous observation of CAPN2 sub-cellular localization during the C2.7 cell differentiation. Cytoplasmic localization was correlated with the differentiation status of the myotubes (Raynaud et al., 2004).

In summary, we show that capn2 is expressed during mouse embryonic development as soon as the first cell divisions, and maintained during later stages in specific cell types at the nuclear level. Previous expression analysis of the other calpains indicated distinct spatial and temporal patterns. Calpain 3 expression starts in myotome cells at E11.5 in mouse (Fougerousse et al., 1998, 2000). Calpain 4 (the regulatory subunit of calpains) is expressed at the first zygote stages and later on (Arthur et al., 2000; Zimmerman etal., 2000) in an ubiquitous pattern, which is also the case for calpain 1 (Azam et al., 2001). Here we show that CAPN2 is expressed in a ubiquitous pattern at the earliest stages of development and becomes tightly regulated during organogenesis and differentiation steps of development.

Nuclear localization is probably linked to chromosomal activity since transient inactivation in cell culture indicated that CAPN2 is necessary for proper chromosome alignment at the metaphase plate (Honda et al., 2004). Taken together, the results of the targeted capn2gene inactivation (embryonic lethality after the 8-

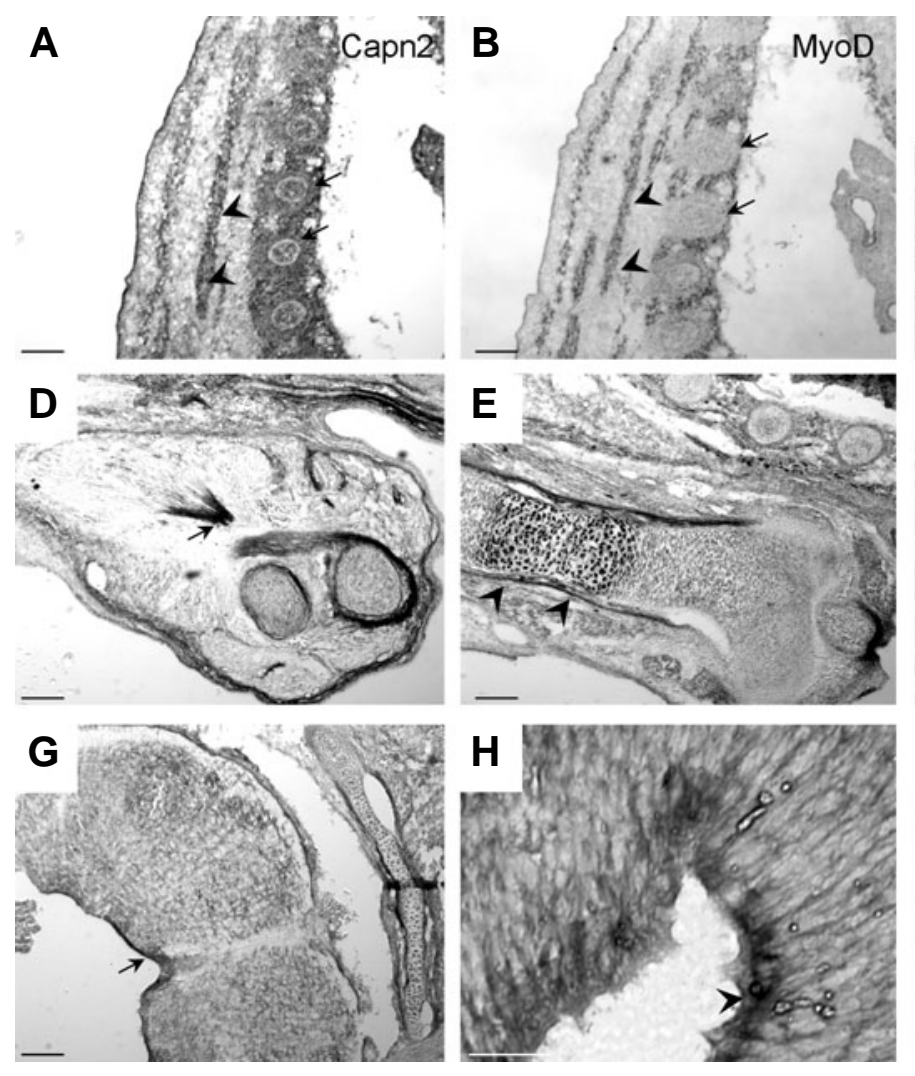

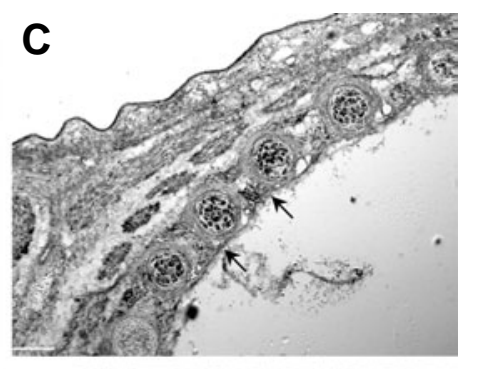
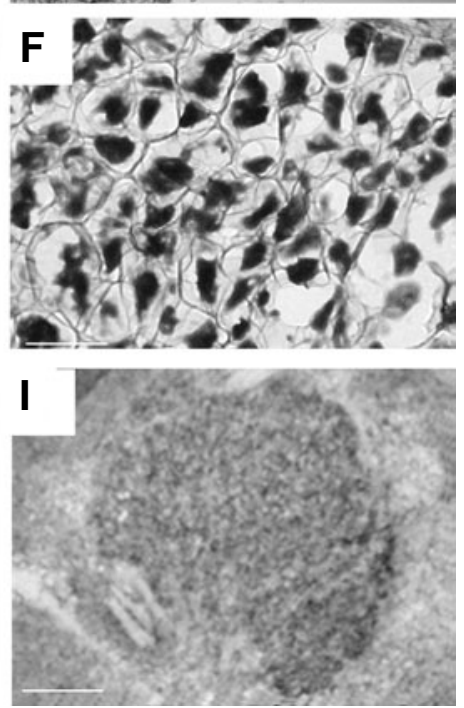

Fig. 4. Calpain2 expression at E14.5. In situ hybridization on 14 $\mu \mathrm{m}$ frozen sections showed capn2 expression in myoblasts (A,B), chondrocytes (C-F) and neural cells (G-I). Sagittal sections through the thorax showing capn2 mRNA in myoblasts (A), identified with myoD probe on adjacent sections(B). Identical precursorgroups were labelled with both markers (arrowheads). Strong signal was also observed in the rib primordia which were devoid of myoD expression; see arrows in (B). Section through the shoulder also showed myoblast labelling; arrow in (D). Labelling of chondrocytes was observed in sections of forelimb bones (D,E) and highermagnification confirmed their hypertrophic status (F). Strong capn2 expression was detected within neural tissue in cells of the ventricular zone at the hindbrain level (Garrow, Harrowhead). Capn2 was expressed in all cells of the trigeminal ganglion (I) but not in other cranial or dorsal root ganglia. Scale bars, $250 \mu \mathrm{m}(A-E, G), 22 \mu \mathrm{m}$ $(F, H, I)$. 

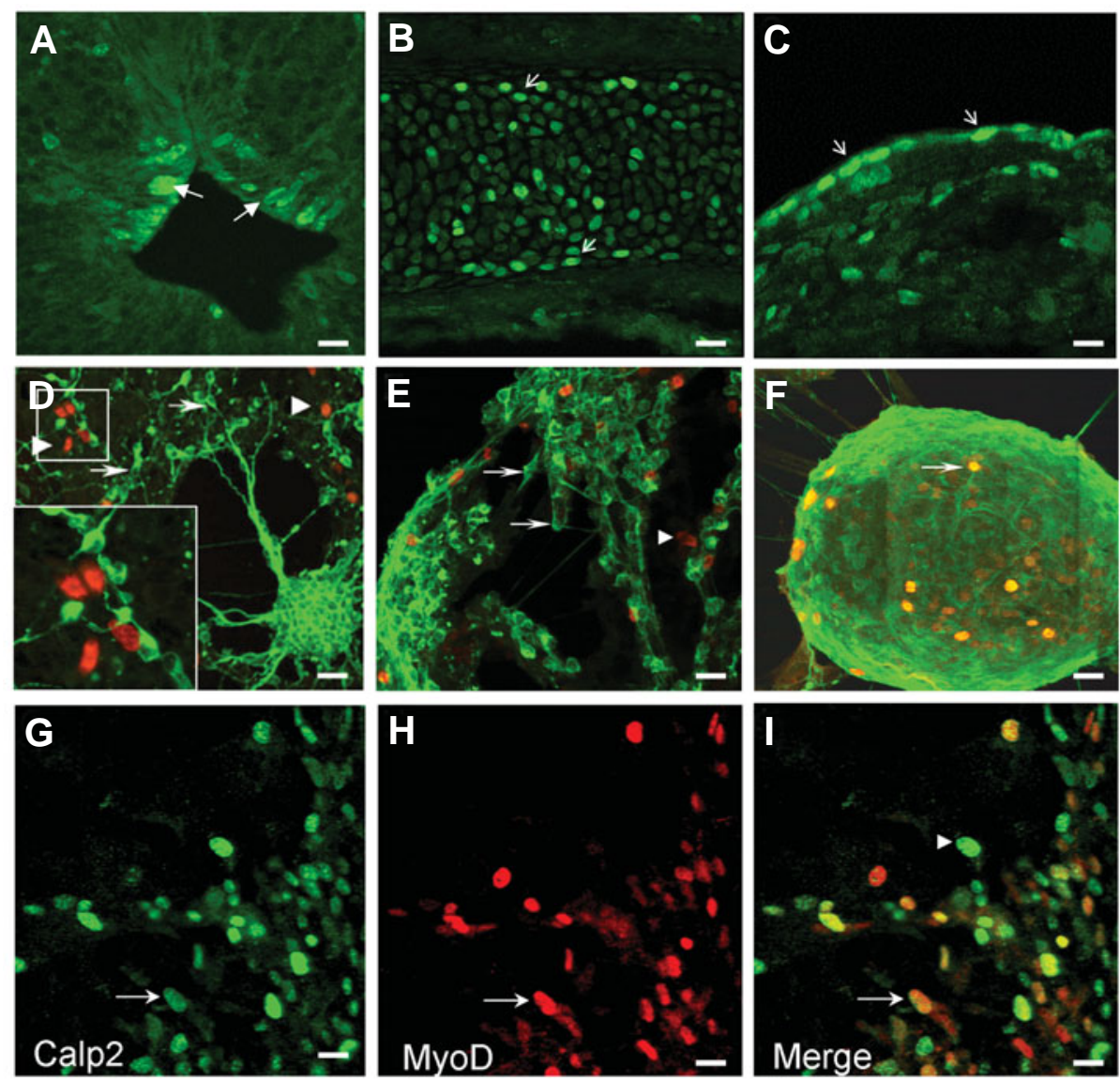

Fig. 5. Nuclear localization of CAPN2 during organogenesis and in explant tissues. On frozen sections, strong expression at the protein level was observed in: neural cells (A), chondrocytes (B) and fibroblasts (C). (A) Prominent nuclear labelling was detected in proliferating neural cells (arrows), and cytoplasmic staining was observed in post-mitotic neurons in the neural tissue. Within the growing epiphysis of the bones, chondrocytes were labelled at the nuclear and cytoplasmic levels ( $B$, arrows). Fibroblasts showed mainly a nuclear CAPN2 localization in the conjonctive tissue $(C$, arrows)). Tissue explants of E10.5 embryos from head and trunk regions generated neurosphere-like structures (D-F) and primary myoblasts (G-I). Immuno-localization of CAPN2 (red, arrowheads) indicates that neuronal cells loose nuclear expression during differentiation, which was assessed by co-labeling with the post-mitotic neuronal marker $\beta 3$ tubulin (green, arrows) (D-F). Neurosphere-like structures with ongoing proliferation maintain nuclear expression (arrow) (F). Myoblasts were identified based upon myoD expression (red, $\mathrm{H}$ ) and co-labelling indicated that most of the myoblasts retained nuclear expression of CAPN2 (arrow, G, I). Fibroblasts were only labelled by CAPN2 antibody (green, arrowhead, I). Scale bar, $10 \mu \mathrm{m}$.

cell developmental stage, Dutt et al., 2006), and the nuclear expression in ES cells as well as the 8-cell embryos, indicate a decisive role during cell mitosis and/or cell cycle regulation. Moreover our present report and previous in vitrodata support the notion that CAPN2 can be shuttled between nuclear and cytosolic compartments and has distinct functions in proliferating and differentiated cells (Shao et al., 2006). These data constitute a strong basis to understand the role of CAPN2 during embryonic development.

\section{Materials and Methods}

\section{Animals}

All experiments were conducted in accordance with the European
Communities Council Directive and INSERM guidelines. Pregnant OF1 mice were purchased from Charles River Research Laboratories (L'Arbresle, France). The day after nocturnal mating was considered as embryonic day $(E)$ 0.5 . 8-cell stage embryos were collected between 68 and 72 hours after the record of the vaginal plug. Embryos were flushed from the oviducts with culture medium, staged and then fixed in PFA4\% (Honda et al., 2005). For In situ hybridization (ISH) and immunohistochemistry, embryos were obtained from pregnant females at $E 8.5$ to 14.5 stages. Embryos were collected in cold PBS, fixed by immersion in $4 \%$ paraformaldehyde, dehydrated in methanol, and stored at $-20^{\circ} \mathrm{C}$ until processing. After re-hydration, whole embryos or sagittal cryostat sections $(14 \mu \mathrm{M})$ were processed for ISH.

\section{In situ hybridization}

We used mouse and human capn2 cDNA as templates for riboprobe: the human full length cDNA fragment (GenBank Accession number: M23254) shows $88 \%$ identity with the mouse cDNA (GenBank Accession number Y10139) (cloning vector pCAF1-calp2). The sequence verified clone IRAVp968F10124D6 containing the mouse cDNA was obtained from the RZPD resource center. The mouse probe gave the same results as the human probe on wholemount embryos as well as on cryostat sections. The myoD probe corresponded to the mouse myoD cDNA (GenBank Accession number: M18779, (Davis et al., 1987)).

We used digoxigenin-labeled probes as described previously (Manley and Capecchi, 1995, Poluch et al., 2003). Hybridization signal was detected using alkaline phosphatase-conjugated antibodies against digoxigenin (Roche, Mannheim, Germany) and BM purple substrate (Roche). Whole-mount embryo ISH was performed as previously described (Carroll et al., 2001, Goddard et al., 1996). Hybridization with the sense probes was performed on control embryos and serial frozen sections under the same conditions; no signal was detected in examined tissues. Vibratome sections $(30 \mu \mathrm{m})$ were carried out after clearing the embryos through serial glycerol solutions.

\section{Immunocytochemistry}

Immunofluorescent staining was performed on ES cells and 8-cell stage embryos as described previously (Raynaud et al., 2004). Wholemount immunostaining was performed on E8.5 embryos as described previously using a secondary antibody against mouse IgG conjugated to horseradish peroxydase diluted at 1/400 (Jackson) (Rossel and Capecchi, 1999).

Mouse monoclonal antibodies against $\beta 3$ tubulin (Sigma) and against MyoD (Pharmingen) were diluted to 1/200. Rabbit anti-calpain2 was used at $1 / 100$ as described previously (Raynaud et al., 2004). Secondary antibodies directed against mouse IgG or rabbit IgG were conjugated to rhodamine or FITC (Santa Cruz); both combinations were used.

\section{Explant tissue culture and embryonic stem cells}

E10.5 embryos were dissected and tissues were placed in skeletal 
muscle growth medium (Pharmingen), maintained for 5 days in standard culture conditions and processed for immunocytochemistry. ES cell line BS1 was cultured as described previously (Papadimou et al., 2005) and processed for immunofluorescence.

\section{Acknowledgements}

This work was supported by EPHE, CNRS and INSERM. FR was supported by the Association Française contre les Myopathies (AFM). We thank Pr Puceat for the gift of mouse ES cells (Centre de Recherches de Biochimie Macromoleculaire, Montpellier, France).

\section{References}

ARTHUR, J.S., ELCE, J.S., HEGADORN, C., WILLIAMS, K. and GREER, P.A. (2000). Disruption of the murine calpain small subunit gene, Capn4: calpain is essential for embryonic development but not for cell growth and division. Mol Cell Bio/20: 4474-81.

AZAM, M., ANDRABI, S.S., SAHR, K.E., KAMATH, L., KULIOPULOS, A. and CHISHTI, A.H. (2001). Disruption of the mouse mu-calpain gene reveals an essential role in platelet function. Mol Cel/ Bio/21: 2213-20.

CARILLO, S., PARIAT, M., STEFF, A., JARIEL-ENCONTRE, I., POULAT, F., BERTA, P. and PIECHACZYK, M. (1996). PEST motifs are not required for rapid calpain-mediated proteolysis of c-fos protein. Biochem J313 ( Pt 1): 24551.

CARROLL, P., GAYET, O., FEUILLET, C., KALLENBACH, S., DE BOVIS, B., DUDLEY, K. and ALONSO, S. (2001). Juxtaposition of CNR protocadherins and reelin expression in the developing spinal cord. Mol Cel/Neurosci17: 61123.

DAVIS, R.L., WEINTRAUB, H. and LASSAR, A.B. (1987). Expression of a single transfected cDNA converts fibroblasts to myoblasts. Cel/51: 987-1000.

DEDIEU, S., MAZERES, G., DOURDIN, N., COTTIN, P. and BRUSTIS, J.J. (2003). Transactivation of capn 2 by myogenic regulatory factors during myogenesis. $J$ Mol Bio/326: 453-65.

DUTT, P., CROALL, D.E., ARTHUR, S.C., DE VEYRA, T., WILLIAMS, K., ELCE, J.S. and GREER, P.A. (2006). m-Calpain is required for preimplantation embryonic development in mice. BMC Dev Bio/6: 3 .

FOUGEROUSSE, F., DURAND, M., SUEL, L., POURQUIE, O., DELEZOIDE, A.L., ROMERO, N.B., ABITBOL, M. and BECKMANN, J.S. (1998). Expression of genes (CAPN3, SGCA, SGCB, and TTN) involved in progressive muscular dystrophies during early human development. Genomics 48: 145-56.

FRANCO, S., PERRIN, B. and HUTTENLOCHER, A. (2004). Isoform specific function of calpain 2 in regulating membrane protrusion. Exp Cel/ Res299: 17987.

GODDARD, J.M., ROSSEL, M., MANLEY, N.R. and CAPECCHI, M.R. (1996). Mice with targeted disruption of Hoxb-1 fail to form the motor nucleus of the VIlth nerve. Development 122: 3217-28.

GOLDMAN, D.C., MARTIN, G.R. and TAM, P.P. (2000). Fate and function of the ventral ectodermal ridge during mouse tail development. Development 127: 2113-23.

HAUBENSAK, W., ATTARDO, A., DENK, W. and HUTTNER, W.B. (2004). Neurons arise in the basal neuroepithelium of the early mammalian telencephalon: a major site of neurogenesis. Proc Natl Acad Sci USA 101: 3196-201.

HONDA, S., MARUMOTO, T., HIROTA, T., NITTA, M., ARIMA, Y., OGAWA, M. and SAYA, H. (2004). Activation of $m$-calpain is required for chromosome alignment on the metaphase plate during mitosis. J Biol Chem 279: 10615-23.
HONDA, Y., TANIKAWA, H., FUKUDA, J., KAWAMURA, K., SATO, N., SATO, T., SHIMIZU, Y., KODAMA, H. and TANAKA, T. (2005). Expression of Smac/ DIABLO in mouse preimplantation embryos and its correlation to apoptosis and fragmentation. Mol Hum Reprod 11: 183-8.

HUTTENLOCHER, A., PALECEK, S.P., LU, Q., ZHANG, W., MELLGREN, R.L., LAUFFENBURGER, D.A., GINSBERG, M.H. and HORWITZ, A.F. (1997). Regulation of cell migration by the calcium-dependent protease calpain. J Biol Chem 272: 32719-22.

KONIG, N., RAYNAUD, F., FEANE, H., DURAND, M., MESTRE-FRANCES, N., ROSSEL, M., OUALI, A. and BENYAMIN, Y. (2003). Calpain 3 is expressed in astrocytes of rat and Microcebus brain. J Chem Neuroanat 25: 129-36.

MANLEY, N.R. and CAPECCHI, M.R. (1995). The role of Hoxa-3 in mouse thymus and thyroid development. Development 121: 1989-2003.

MURRAY, S.S., GRISANTI, M.S., BENTLEY, G.V., KAHN, A.J., URIST, M.R. and MURRAY, E.J. (1997). The calpain-calpastatin system and cellular proliferation and differentiation in rodent osteoblastic cells. Exp Cell Res 233: 297-309.

PAPADIMOU, E., MENARD, C., GREY, C. and PUCEAT, M. (2005). Interplay between the retinoblastoma protein and LEK1 specifies stem cells toward the cardiac lineage. EMBO J24: 1750-61.

POLUCH, S., ROSSEL, M. and KONIG, N. (2003). AMPA-evoked ion influx is strongest in tangential neurons of the rat neocortical intermediate zone close to the front of the migratory stream. Dev Dyn 227: 416-21.

QIN, C., BURGHARDT, R., SMITH, R., WORMKE, M., STEWART, J. and SAFE, S. (2003). Peroxisome proliferator-activated receptor gamma agonists induce proteasome-dependent degradation of cyclin D1 and estrogen receptor alpha in MCF-7 breast cancer cells. Cancer Res 63: 958-64.

RAYNAUD, F., CARNAC, G., MARCILHAC, A. and BENYAMIN, Y. (2004). mCalpain implication in cell cycle during muscle precursor cell activation. Exp Cell Res 298: 48-57.

ROSSEL, M. and CAPECCHI, M.R. (1999). Mice mutant for both Hoxa1 and Hoxb1 show extensive remodeling of the hindbrain and defects in craniofacial development. Development 126: 5027-40.

SHAO, H., CHOU, J., BATY, C.J., BURKE, N.A., WATKINS, S.C., STOLZ, D.B. and WELLS, A. (2006). Spatial localization of $m$-calpain to the plasma membrane by phosphoinositide biphosphate binding during epidermal growth factor receptormediated activation. Mol Cel/ Biol26: 5481-96.

TAM, P.P., GOLDMAN, D., CAMUS, A. and SCHOENWOLF, G.C. (2000). Early events of somitogenesis in higher vertebrates: allocation of precursor cells during gastrulation and the organization of a meristic pattern in the paraxial mesoderm. Curr Top Dev Bio/47: 1-32.

TREMPER-WELLS, B. and VALLANO, M.L. (2005). Nuclear calpain regulates $\mathrm{Ca} 2+-$ dependent signaling via proteolysis of nuclear $\mathrm{Ca} 2+$ /calmodulin-dependent protein kinase type IV in cultured neurons. J Biol Chem 280: 2165-75.

WATT, F. and MOLLOY, P.L. (1993). Specific cleavage of transcription factors by the thiol protease, m-calpain. Nucleic Acids Res 21: 5092-100.

WELM, A.L., TIMCHENKO, N.A., ONO, Y., SORIMACHI, H., RADOMSKA, H.S., TENEN, D.G., LEKSTROM-HIMES, J. and DARLINGTON, G.J. (2002). C/ EBPalpha is required for proteolytic cleavage of cyclin $A$ by calpain 3 in myeloid precursor cells. J Biol Chem 277: 33848-56.

YASUDA, T., SHIMIZU, K., NAKAGAWA, Y., YAMAMOTO, S., NIIBAYASHI, H. and YAMAMURO, T. (1995). m-calpain in rat growth plate chondrocyte cultures: its involvement in the matrix mineralization process. Dev Biol170: 159-68.

ZIMMERMAN, U.J., BORING, L., PAK, J.H., MUKERJEE, N. and WANG, K.K. (2000). The calpain small subunit gene is essential: its inactivation results in embryonic lethality. IUBMB Life 50: 63-8. 


\section{Related, previously published Int. J. Dev. Biol. articles}

See our Special Issue Mammalian Reproduction \& Development in honor of Anne McLaren and edited by Brigid Hogan at: http://www.ijdb.ehu.es/web/contents.php?vol=45\&issue=3

See our Special Issue Ear Development edited by Fernando Giraldez and Bernd Fritzsch at:

http://www.ijdb.ehu.es/web/contents.php?vol=51\&issue=6-7

Spatiotemporal expression of the creatine metabolism related genes agat, gamt and ct1 during zebrafish embryogenesis

Lifeng Wang, Ying Zhang, Ming Shao and Hongwei Zhang

Int. J. Dev. Biol. (2007) 51: 247-253

Cloning and pattern of expression of the shiro-uo vasa gene during embryogenesis and its roles in PGC development

Akimitsu Miyake, Taiju Saito, Tohru Kashiwagi, Daisuke Ando, Akitsugu Yamamoto, Tohru Suzuki, Norio Nakatsuji and Takako Nakatsuji

Int. J. Dev. Biol. (2006) 50: 619-625

Mechanics in embryogenesis and embryonics: prime mover or epiphenomenon?

Richard Gordon

Int. J. Dev. Biol. (2006) 50: 245-253

Effects of microgravity on cell cytoskeleton and embryogenesis

Susan J. Crawford-Young

Int. J. Dev. Biol. (2006) 50: 183-191

Tracing the hemangioblast during embryogenesis: developmental relationships between endothelial and hematopoietic cells

Thierry Jaffredo, Karine Bollerot, Daisuke Sugiyama, Rodolphe Gautier and Cécile Drevon

Int. J. Dev. Biol. (2005) 49: 269-277

M-calpain levels increase during fusion of myoblasts in the mutant muscular dysgenesis ( $\mathrm{mdg}$ ) mouse.

$S$ Joffroy, N Dourdin, J P Delage, P Cottin, J Koenig and J J Brustis Int. J. Dev. Biol. (2000) 44: 421-428

2006 ISI **Impact Factor $=3.577^{\star *}$

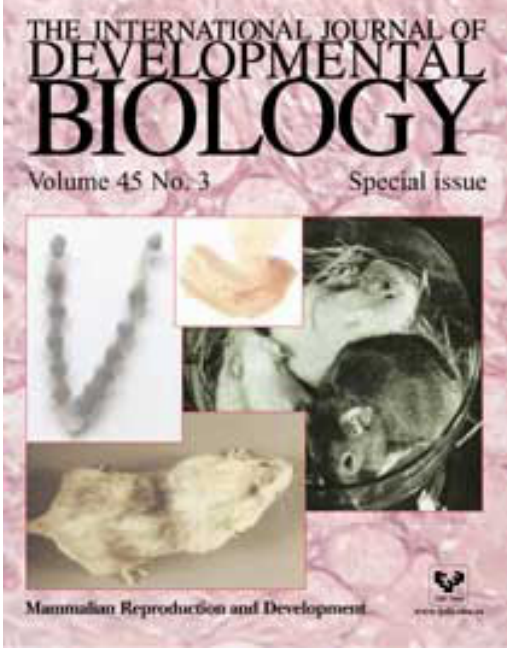

